\title{
Worth Their Salt: One Hundred Years of Hyperosmolar Therapy
}

\author{
Bart Lutters $^{\mathrm{a}}$ Peter J. Koehler ${ }^{\mathrm{b}}$ Eelco F. Wijdicks ${ }^{\mathrm{c}}$ \\ aJulius Center, Medical Humanities, University Medical Center Utrecht, Utrecht, The Netherlands; ${ }^{\mathrm{b}}$ Faculty of Health, \\ Medicine \& Life Sciences, Maastricht University, Maastricht, The Netherlands; ${ }^{c}$ Mayo Clinic, Rochester, NY, USA
}

\section{Keywords}

History of medicine $\cdot$ Hyperosmolar therapy $\cdot$ Intracranial pressure $\cdot$ Hypertonic saline $\cdot$ Mannitol

\begin{abstract}
In this article, we commemorate the centenary of the discovery and clinical implementation of hyperosmolar therapy for the treatment of increased intracranial pressure (ICP). Following the pioneering work of anatomists Weed and McKibben in 1919, the use of hypertonic solutions was soon adopted into clinical practice, even though the preferred hypertonic agent, route of administration, and ideas regarding the physiological mechanism by which it reduced ICP diverged. These divergent conceptions and practices have continued to surround the use of hyperosmolar therapy into present times.

(c) 2020 The Author(s)

Published by S. Karger AG, Basel
\end{abstract}

\section{Introduction}

Most neurologists and neurosurgeons are familiar with the use of mannitol or hypertonic saline in emergency situations where patients acutely deteriorate from brain shift. Indeed, hyperosmolar therapy is a recognized

karger@karger.com www.karger.com/ene

Karger $\stackrel{\text { ' }}{=}$
(C) 2020 The Author(s)

Published by S. Karger AG, Basel

This article is licensed under the Creative Commons AttributionNonCommercial-NoDerivatives 4.0 International License (CC BY NC-ND) (http://www.karger.com/Services/OpenAccessLicense). Usage and distribution for commercial purposes as well as any distribution of modified material requires written permission. rescue therapy in patients with acute increased intracranial pressure (ICP). In 1919, anatomists Weed and McKibben [1,2], working at the Army Neuro-Surgical Laboratory at Johns Hopkins, first demonstrated the effect of intravenously injected hyperosmolar solutions on reducing ICP and brain volume in cats. While Weed and McKibben's main objective was to have a better understanding of intracranial volume relationships, they somewhat serendipitously discovered a new method to combat cerebral edema. Following this discovery, hyperosmolar therapy was quickly applied in clinical practice, even though the preferred hypertonic agent, route of administration, and ideas regarding the physiological mechanism by which it reduced ICP diverged. In this article, we commemorate the centenary of the discovery and clinical implementation of hyperosmolar therapy, a therapeutic modality that is still surrounded by some of the questions that characterized the field one hundred years ago [3].

\section{Relieving the Pressure}

During the first decades of the 20th century, intracranial hypertension came to be regarded as a fundamental problem in the surgical management of nervous system diseases. Accordingly, the problem of cerebrospinal fluid 
Fig. 1. Cerebrospinal fluid pressure in a cat upon intravenous injection of sodium chloride. Injection of a $30 \%$ sodium chloride solution $\left(12 \mathrm{~cm}^{3}\right)$ causes an initial rise in cerebrospinal fluid pressure followed by a rapid and lasting decrease. CSF, cerebrospinal fluid.

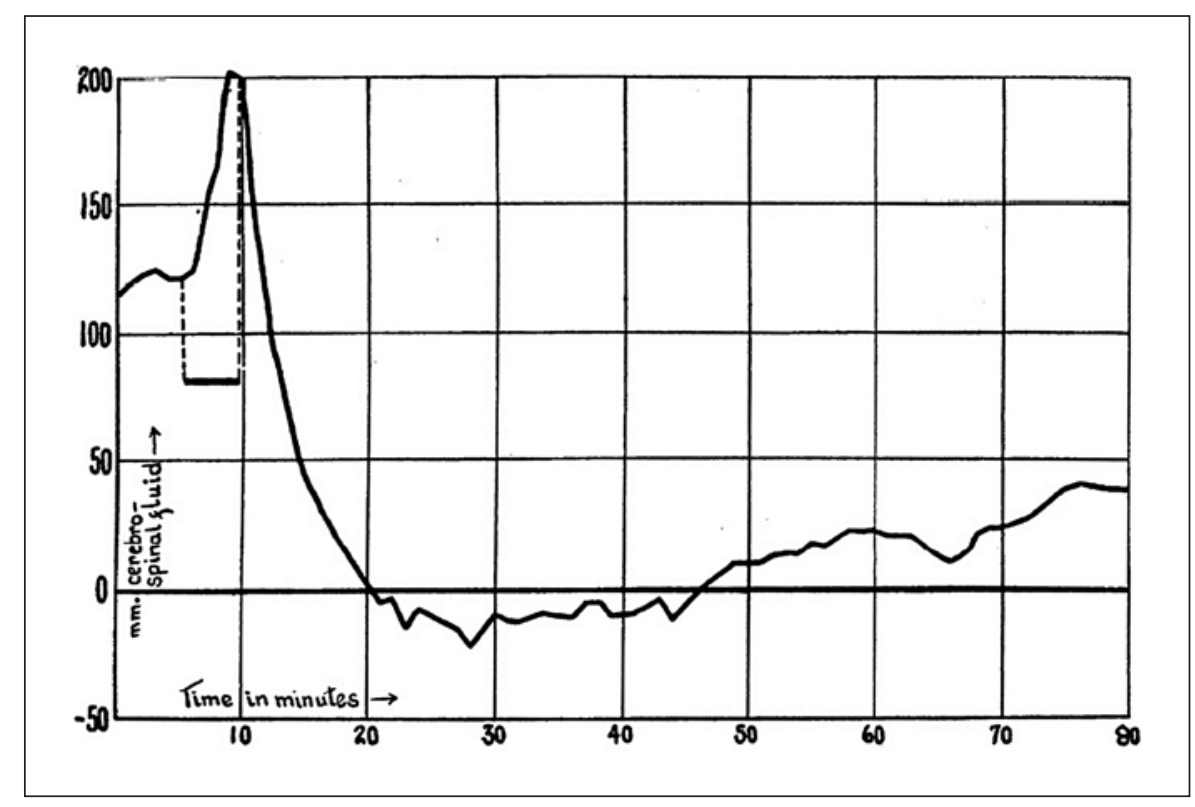

(CSF) dynamics studied by many of the early pioneers of neurological surgery, including Harvey Cushing and Walter Dandy, who consecutively directed the Hunterian Laboratory at Johns Hopkins. It was in this laboratory where talented young physician and researcher Weed [47] became interested in CSF production and reabsorption and the similarities between cerebral and ocular fluids. In one of the experiments, Weed, in collaboration with his colleague McKibben, sought to determine whether intravenously injected salt would lead to an increased amount of salt present in CSF. Following intravenous salt injection, however, the researchers found that they could no longer obtain CSF from the spinal subarachnoid space. Hypothesizing that the salt injections had somehow reduced the volume and pressure of CSF, they quickly attached a manometer to the puncture needle for continuous pressure measurements. This experimental setup soon revealed that CSF pressure was altered "very rapidly and very definitely" by intravenous solutions of various osmolarity [1].

In their experiments, Weed and McKibben exposed ether-anesthetized cats to isotonic, hypotonic, and hypertonic solutions. For pressure measurements, the occipitoatlantoid ligament was punctured and the puncture needle attached to a manometer. Following the intravenous injection of Ringer's solution (isotonic to the blood), no lasting pressure changes were observed. Intravenous injection of distilled water (hypotonic to the blood), on the other hand, resulted in a prompt increase in ICP, which

One Hundred Years of Hyperosmolar Therapy remained high for the duration of the experiment. The reverse was true for intravenous injections of various hypertonic solutions - including sodium chloride, sodium bicarbonate, sodium sulfate, and glucose - which led to a brief initial rise in pressure (caused by mechanical pressure of the injection and intravenous volume expansion) followed by a lasting decrease (Fig. 1). Of the different hypertonic solutions, the sodium chloride $30 \%$ solution was found to be the most potent, even though its use was frequently accompanied by severe respiratory and cardiac disturbances.

Weed and McKibben [1] hypothesized that the effect of hypotonic and hypertonic solutions on CSF pressure was likely caused by alterations in the osmotic value of the blood, leading to "fluid readjustment within the tissues." The assumption that hypotonic and hypertonic solutions brought about a change in CSF pressure through fluid displacement between blood and tissue gave rise to the question whether changes in CSF pressure were accompanied by alterations in brain volume [2].

\section{Alteration of Brain Volume}

To investigate the relationship between CSF pressure and brain volume, Weed and McKibben again exposed ether-anesthetized cats to intravenous isotonic, hypotonic, and hypertonic solutions. About half an hour after the injections, the animals were sacrificed and their brains 
preserved in formalin, allowing for a rough comparison of brain size and structure between animals exposed to different solutions. As the exact form and size relations could, however, not be preserved by this method of fixation, they also conducted experiments on cats with unilateral or bilateral trephine openings, enabling them to directly observe changes in brain volume following intravenous injections in life animals [2].

In cats without trephine openings, postmortem brains appeared normal when cats had been exposed to intravenous Ringer's solution. The brains of cats exposed to hypotonic or hypertonic solutions, however, showed definite changes: whereas the brains of cats exposed to distilled water were evidently swollen upon macroscopic and microscopic analysis, the brains of cats exposed to salt solutions showed a marked decrease in volume. Observations in cats with trephine openings corresponded to these findings: following the intravenous injection of distilled water, the brains of these cats protruded through the trephine opening, whereas intravenous salt injections would cause them to fall under the skull surface [2].

Based on their findings, Weed and McKibben concluded that the traditional view of the brain as an incompressible organ was no longer valid. In contrast to the influential Monro-Kellie doctrine, Weed and McKibben argued the intracranial volume dynamics were governed by 3 dynamic components - blood, CSF, and brain tissue - and that a volume change in any of these would result in compensation by the others. The effect of solutions of various osmolarity on CSF pressure, then, could at least in part be explained by displacement of fluid between brain tissue and blood. In addition, the displacement of CSF from the subarachnoid space into the bloodstream following the intravenous injection of hypertonic solutions was also thought to play a role in lowering the CSF pressure [2].

\section{Clinical Implementation}

The findings by Weed and McKibben were immediately adopted into clinical practice. In the same year, Detroit physician Haden [8] reported that he had successfully treated 2 patients with hypertonic solutions. Haden preferred the use of glucose solutions over other hypertonic agents, stimulated by previous reports on the merits of intravenous hypertonic glucose injections in patients deteriorating from various clinical conditions [9]. Haden's first patient suffered from meningitis, which he had initially treated with intraspinal "immune serum" (animal- derived antibodies targeted against meningococci) and repeated lumbar punctures. When the patient became comatose, he administered a $25 \%$ glucose solution intravenously as a last resort, which led to "marked improvement." The following day, after a second glucose injection, the patients "became rational and made an uneventful recovery without further treatment of any kind." The second patient, diagnosed with measles with cerebral involvement, made a similar recovery following glucose injections. Referring to the experiments by Weed and McKibben, Haden argued that, in these cases, the positive effect of glucose injections was likely due to a "decrease in the ICP brought about by a change in the bulk of the brain" [8].

In 1920, neurosurgeons Sachs and Belcher [10], working at Washington University (St. Louis) reported on the use of hypertonic solutions during brain tumor surgery. In such cases, the brain was often under so much tension that the cortex would rupture when the dura was opened, making removal of the tumor without causing extensive brain damage impossible. In their report, Sachs and Belcher [10] described a patient whose ICP, upon intraoperative intravenous administration of a saturated salt solution, decreased to such an extend that "a tumor of considerable size in the temporo-occipital region could be removed." Even though the authors saw great potential in the intraoperative use of salt solutions - particularly in cases where the brain tumor compressed the ventricles, deeming the use of ventricular puncture impossible they stressed that the procedure should be used guardedly until the potential dangers of salt in such concentrations had been identified [10].

While Haden (1919) and Sachs and Belcher (1920) successfully applied the findings by Weed and McKibben into the clinic, they did not seek to establish the physiological mechanism underlying the effect of hypertonic solutions on ICP in human subjects. In 1920, surgeon Frederic Foley, in collaboration with Harvey Cushing, made an important contribution with this respect $[11,12]$. Foley first established the effect of hypertonic salt solutions on CSF pressure in humans. As was the case for laboratory animals, Foley showed that the intravenous administration of hypertonic salt solutions led to a significant decrease in CSF pressure in humans. Moreover, he found that the gastro-intestinal administration of hypertonic salt solutions had the same effect on CSF pressure as intravenous administration. Because of the potential respiratory and cardiac disturbances associated with intravenous injections, Foley generally preferred the gastro-intestinal route. 
Fig. 2. Patient with a protrusion following decompressive craniectomy before (a) and $2 \mathrm{~h}$ after (b) intravenous injection of a $15 \%$ sodium chloride solution $\left(120 \mathrm{~cm}^{3}\right)$. c Apparatus described by Frederic Foley to measure changes in the brain volume and CSF pressure. A balloon-containing cast was placed over the protrusion of patients who underwent decompressive craniectomy. The balloon was connected to a manometer and a water reservoir. With this setup, the protrusion could be subjected to a constant pressure while brain volume change could be measured by the amount of fluid displaced out of the reservoir. CSF, cerebrospinal fluid.
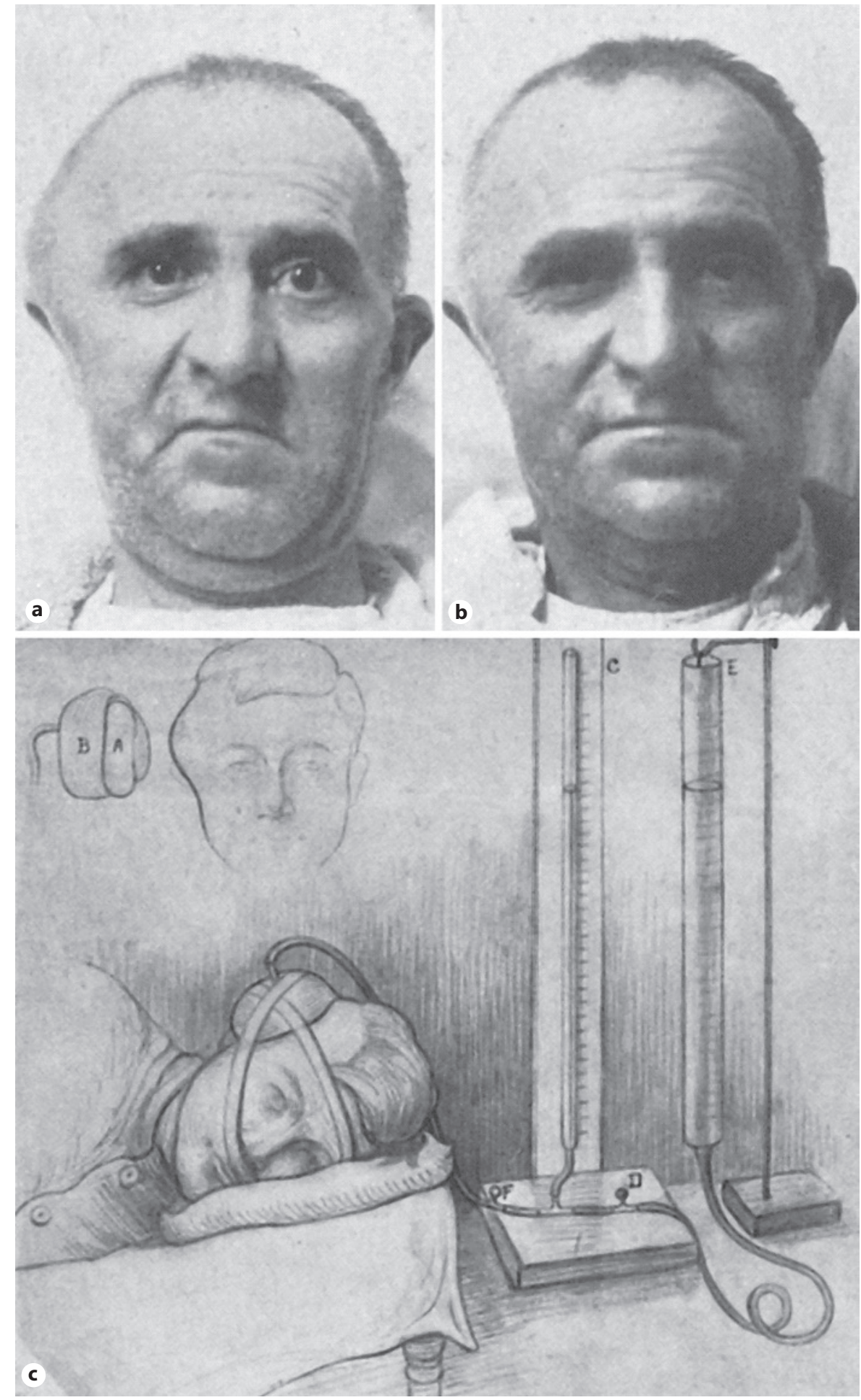

Similar to Weed and McKibben, Foley then set out to determine whether a decrease in CSF pressure following the administration of hypertonic salt was associated with a decrease in brain volume. Whereas Weed and McKib- ben had made use of trephine openings in cats, Foley relied on observations on patients who had undergone decompressive craniectomies, a procedure that was often followed by a noticeable protrusion of the brain under the 
skin. Foley found that the protrusions in these patients significantly decreased upon oral administration of hypertonic salt (Fig. 2a, b). He confirmed these observations using an apparatus he called a "balloon-cast-manometer system," which allowed him to graphically depict the concurrent decrease in CSF pressure and volume over the protrusion following salt ingestion (Fig. 2c). In line with Weed and McKibben, Foley concluded that the effect of hypertonic salt on CSF pressure was due to an increased osmotic value of the blood, leading to the displacement of fluid into the bloodstream. As Foley noted, however, that patients with ventricular dilation showed a more pronounced decrease in brain volume than patients without such dilation, he argued that the displaced fluid primarily originated from increased absorption of CSF from the ventricles, rather than from the brain tissue itself [12].

In addition to his physiological experiments, Foley summarized the conditions where hypertonic solutions would be of clinical usefulness, including brain tumors, particularly attended by ventricular dilation, meningitis, and "pressure headache." Moreover, he emphasized the diagnostic value of hypertonic solutions, stating that "symptoms of localizing value may be brought to light which under conditions of increased tension could not be elicited" [12]. This view was shared by Philadelphia neurosurgeon Fay [13], who was the first to suggest the use of hypertonic solutions in the treatment of traumatic brain injury, favoring rectal magnesium sulfate over other agents, and means of administration.

In addition to hyperosmolar therapy, Fay advocated the restriction of fluid intake to further stimulate the transport of fluid from the brain to the circulation in cases of increased ICP. Interestingly, dehydration by purgation as a means to combat cerebral edema had already been described by Edinburgh physician Byrom Bramwell (1847-1931) in the late 1880s [14-16].

\section{The Fall and Rise of Hyperosmolar Therapy}

Despite initial enthusiasm, the use of hypertonic solutions for the treatment of increased ICP did not remain undisputed. For one, it was argued that the decrease in ICP brought about by hypertonic solutions was only transient and was often followed by a secondary rise in pressure [17]. Others pointed at the cardiac, respiratory, and renal problems associated with hyperosmolar therapy [18]. Most of these adverse events resulted from electrolyte disbalance following the administration of large doses of hypertonic solutions. As a result of these criticisms, the use of hypertonic solutions started to rapidly fall out of favor by the middle of the 1930s. In the 1940s, the use of plastic particles as a hyperosmotic agent for the treatment of increased ICP was introduced in the German literature, but the procedure was not widely accepted [19, 20]. In the late 1950s, neurosurgeons Javid and Settlage [21] introduced the use of urea for the treatment of increased ICP. While urea was initially adopted for the treatment of brain tumors and traumatic brain injury, the introduction of mannitol by Burton Wise and Norman Chater in 1961 led to its eventual displacement, as mannitol proved to be easier to prepare and store and was less likely to cause venous irritation or phlebitis [22-25]. The early 1960s also witnessed the introduction of invasive continuous ICP monitoring by Swedish neurosurgeon Nils Lundberg, a technique that provided neurologists and neurosurgeons with an objective sign of increased ICP and, subsequently, grew out to be an important - albeit not undisputed - guide to establish the indication for hyperosmolar therapy in the intensive care setting [26].

\section{Conclusion}

The history of pharmacy in neurology has been a relatively neglected subject. Nevertheless, the discovery of hyperosmolar agents for the treatment of cerebral edema was a phenomenal breakthrough. Following the pioneering work by Weed and McKibben, the use of hypertonic solutions was quickly translated from bench to bedside. From the very beginning, however, individual physicians have favored different hypertonic agents and means of administration, and have had different understandings of the mechanism of action. While the past century has witnessed the rise and fall of various hypertonic agents, these individual differences continue to exist. Hypertonic saline has recently staged a comeback, and while mannitol and hypertonic saline both seem to be effective in reducing ICP, divergent views on their comparative merits and side effects, the optimal means of administration, ways of monitoring, and the mechanism of action continue to exist [27-30]. Despite these continuing debates, the introduction of hyperosmolar therapy remains one of the most consequential discoveries in the history of acute neurology.

\section{Statement of Ethics}

The authors have no ethical conflicts to disclose. 


\section{Conflict of Interest Statement}

The authors report no conflicts of interest.

\section{Funding Sources}

The authors declare that no funds have been received.

\section{Author Contributions}

B.L. conceptualized the study and drafted the manuscript for intellectual content. P.K. conceptualized the study and revised the manuscript for intellectual content. E.W. conceptualized the study and revised the manuscript for intellectual content.

\section{References}

1 Weed LH, McKibben PS. Pressure changes in the cerebro-spinal fluid following intravenous injection of solutions of various concentrations. Am J Physiol. 1919;48(4):512-30

2 Weed LH, McKibben PS. Experimental alteration of brain bulk. Am J Physiol. 1919;48(4): $531-58$.

3 Carney N, Totten AM, O'Reilly C, Ullman JS, Hawryluk GW, Bell MJ, et al. Guidelines for the management of severe traumatic brain injury, fourth edition. Neurosurgery. 2016; 80(1):6-15.

4 Weed LH. Studies on cerebro-spinal fluid. No. II: the theories of drainage of cerebro-spinal fluid with an analysis of the methods of investigation. J Med Res. 1914;31(1):21-49.

5 Weed LH. Studies on cerebro-spinal fluid. No. III: the pathways of escape from the subarachnoid spaces with particular reference to the arachnoid villi. J Med Res. 1914;31(1):5191.

6 Weed LH. Studies on cerebro-spinal fluid. No. IV: the dual source of cerebro-spinal fluid. J Med Res. 1914;31(1):93-11.

7 Wagefarth P, Weed LH. Studies on cerebrospinal fluid; the analogous processes of the cerebral and ocular fluids. J Med Res. 1914;31: $167-76$.

8 Haden RL. Therapeutic application of the alteration of brain volume. JAMA. 1919;73(13): 983-4.

9 Litchfield L. Glucose intravenously as a therapeutic measure. JAMA. 1918;71(7):503-5.

10 Sachs E, Belcher GW. Use of saturated salt solution intravenously during intracranial operations: preliminary report. JAMA. 1920;75: $667-8$.
11 Cushing H, Foley FEB. Alterations of intracranial tension by salt solutions in the alimentary canal. Exp Biol Med. 1920;17(8):217-8.

12 Foley FEB. Clinical uses of salt solution in conditions of increased intracranial tension. Surg Gynecol Obstet. 1921;33:126-36.

13 Fay T. The administration of hypertonic salt solutions for the relief of intracranial pressure. JAMA. 1923;80(20):1445-8.

14 Bramwell B. Intracranial tumours. Edinburgh: Young J. Pertland; 1888. p. 245-54.

15 Bramwell B. A case of cerebellar tumor of unusual clinical and pathological interest. Rans Med Chir Soc Edinb. 1888;6:29-56.

16 Leslie G, Bramwell B. A case of cerebral tumour. With pathological report. Trans Med Chir Soc Edinb. 1888;6:23-9.

17 Penfield W. The principles op physiology involved in the management of increased intracranial pressure. Ann Surg. 1935;102(4):54854.

18 Browder J. Dangers in the use of hypertonic solutions in the treatment of brain injuries. Am J Surg. 1930;8(6):1213-7.

19 Jorns G. Osmotische Entwasserung by Hirndruck durch hypertonische Losungen mit Kolloid zusatz. Arch klin Chir. 1940;198:639_ 49.

20 Heep W. Konservative Behandlung des veranderten intrakraniellen Druckes. Ein Beitrag zur Geschichte der Osmotherapie. Zbl Neurochirurgie. 1941;6:67-93.

21 Javid M, Settlage P. Effect of urea on cerebrospinal fluid pressure in human subjects; preliminary report. J Am Med Assoc. 1956; 160(11):943-9.
22 Rocque GB. Manucher Javid, urea, and the rise of osmotic therapy for intracranial pressure. Neurosurgery. 2012;70(5):1049-54.

23 Wise BL, Chater N. Use of hypertonic mannitol solutions to lower cerebrospinal fluid pressure and decrease brain bulk in man. Surg Forum. 1961;12:398-9.

24 Wise BL, Chater N. Effect of mannitol on cerebrospinal fluid pressure. The actions of hypertonic mannitol solutions and of urea compared. Arch Neurol. 1961;4:200-2.

25 Wise BL, Chater N. The value of hypertonic mannitol solution in decreasing brain mass and lowering cerebro-spinal-fluid pressure. J Neurosurg. 1962;19:1038-43.

26 Sonig A, Jumah F, Raju B, Patel NV, Gupta G, Nanda A. The historical evolution of intracranial pressure monitoring. World Neurosurg. 2020;138:491-7.

27 Kamel H, Navi BB, Nakagawa K, Hemphill JC, Ko NU. Hypertonic saline versus mannitol for the treatment of elevated intracranial pressure: a meta-analysis of randomized clinical trials. Crit Care Med. 2011;39(3):554-9.

28 Mortazavi MM, Romeo AK, Deep A, Griessenauer CJ, Shoja MM, Tubbs RS, et al. Hypertonic saline for treating raised intracranial pressure: literature review with meta-analysis. J Neurosurg. 2012;116(1):210-21.

29 Chesnut RM, Temkin N, Carney N, Dikmen S, Rondina C, Videtta W, et al. A trial of intracranial-pressure monitoring in traumatic brain injury. N Engl J Med. 2012;367(26): 2471-81.

30 Ropper AH. Management of raised intracranial pressure and hyperosmolar therapy. Pract Neurol. 2014;14(3):152-8. 